\title{
THE INFLUENCE OF THE NOCTURNAL BOUNDARY LAYER ON SECONDARY TRACE SPECIES IN THE ATMOSPHERE AT DORSET, ONTARIO
}

\author{
D. R. Hastie, P. B. Shepson, S. Sharma and H. I. SchifF \\ Chemistry Department and Centre for Atmospheric Chemistry, York University, 4700 Keele St., \\ North York, Ontario, Canada M3J 1P3
}

\begin{abstract}
The impact of the nocturnal boundary layer (NBL) on the concentrations of $\mathrm{O}_{3}, \mathrm{H}_{2} \mathrm{O}_{2}, \mathrm{PAN}$ and $\mathrm{CH}_{2} \mathrm{O}$ has been studied for two 4-day periods, one in the summer of 1989 and the other in the spring of 1990. Where the presence of the nocturnal layer is clear, $\mathrm{O}_{3}, \mathrm{PAN}$ and $\mathrm{CH}_{2} \mathrm{O}$ concentrations decrease rapidly and these species appear to be deposited to the surface. Break-up of the inversion in the morning returns concentrations to levels typical of the previous day. $\mathrm{H}_{2} \mathrm{O}_{2}$ is removed much faster than the other species and it is replenished much more slowly. This appears to be due to the $\mathrm{H}_{2} \mathrm{O}_{2}$ dissolving in water droplets resulting from the rapid cooling of the air. There is evidence for a morning maximum in PAN, likely due to the combination of high concentrations being brought downwards during the break-up of the NBL followed by thermal decomposition.
\end{abstract}

Key word index: Ozone, hydrogen peroxide, formaldehyde, PAN, nocturnal boundary layer, deposition, nighttime chemistry.

\section{INTRODUCTION}

Field measurement studies are an important part of the atmospheric chemists' arsenal. They are performed to give data to assist in understanding specific questions in atmospheric chemistry, and for the development and evaluation of photochemical models.

For convenience, most field measurements are made at the surface. However, the presence of the ground, and other local effects, can often significantly impact the observations, masking the larger scale chemical features one wishes to study. One such factor is the occurrence of a strong nocturnal boundary layer (NBL). By isolating the air being sampled from the bulk of the air aloft, for several hours each night, it often plays the principal role in determining the diurnal variation of the surface concentrations of a number of the more reactive species.

In this paper we look in detail at the measurements of a number of secondary, reactive, trace gases, made at a rural site in Ontario, to see the effect of the NBL on their concentrations. The gases under study were $\mathrm{O}_{3}, \mathrm{H}_{2} \mathrm{O}_{2}, \mathrm{CH}_{2} \mathrm{O}$ and PAN. These species have no direct emission sources, with the exception of a small amount of $\mathrm{CH}_{2} \mathrm{O}$ from combustion, and originate from atmospheric oxidation chemistry. By concentrating on these species, it is possible to focus on the chemistry that is occurring, rather than on the emission or transport processes. Furthermore, using the NBL to isolate a relatively small section of the atmosphere accentuates the observable consequences of any of these processes. Although the concentrations of this suite of species would be expected to be related, they have unique atmospheric lifetimes and decay mechanisms, and therefore they constitute a diverse set of molecules with which to probe our understanding of the system.

The behaviour of ozone under the NBL is well documented (e.g. Cox et al., 1975; Harrison et al., 1978; Oltmans, 1981; Kelly et al., 1984; Broder and Gygax, 1985; Broder et al., 1981; Fehsenfeld et al., 1983; Lifshitz et al., 1988; Shepson et al., 1992b). However, the previously reported diurnal behaviour of the other reactive species seldom includes a discussion of the meteorology. For example, daytime maxima in ambient $\mathrm{H}_{2} \mathrm{O}_{2}$ concentrations have been reported by Kins (1990), Olszyna et al. (1988), Jacob et al. (1990), Tanner et al. (1986) and Das et al. (1983), and although Tanner et al. (1986) do suggest the importance of deposition, the variations include no discussion of the importance of the NBL. Claiborn and Aneja (1991) have observed an inverse $\mathrm{H}_{2} \mathrm{O}_{2}$ profile with a maximum at night. These measurements were made on $\mathrm{Mt}$ Mitchell and the concentrations were dominated by the motion of the mixed layer and the daytime minimum was attributed to deposition to vegetation. Formaldehyde measurements by Harris et al. (1989), Mackay et al. (1990) and Martin et al. (1991), show a daytime maximum but again none of these papers discuss the importance of the NBL. For PAN there are several cases (Singh and Salas, 1989; Shepson et al., 1992a, b; Ridley et al., 1990) where the observed nighttime minimum in PAN is attributed to deposition processes but, with the exception of Shepson et al. (1992b), there is little discussion on the importance of the presence of the NBL on this deposition. 
In this paper we present a detailed description of the behaviour of a number of reactive species under the NBL.

\section{EXPERIMENTAL}

The measurements reported here were made as part of a study to examine the atmospheric chemistry at a rural Ontario site. Measurements were made during a summer and a spring campaign at the Ontario Ministry of the Environment's enhanced measurement site at Dorset. Both studies were of 6-weeks duration but here we consider only 4 days from each, 22-25 July 1989 and 25-28 April 1990. Neither period was subject to precipitation, and most of the snow cover had melted before the spring measurements. The site is located in a clearing, in a rural, forested area of centra Ontario, $150 \mathrm{~km}$ northeast of Toronto. Monitoring was performed adjacent to the Air Pollution in Ontario Study (APIOS) station which is at the extreme edge of the Dorset Research Centre. The town of Dorset has a population of less than 1000 , and is located $4 \mathrm{~km}$ to the northeast and appears to exert no influence on the site. The same is true of the local traffic into the Centre. The site is at an elevation of $320 \mathrm{~m}$ in a shallow valley, with the local land being $88 \%$ forested $(75 \%$ deciduous and $25 \%$ coniferous) and $10 \%$ water.

Formaldehyde and hydrogen peroxide were measured using a two-channel tunable diode laser absorption spectrometer (TDLAS). The spectrometer is similar to instruments described in detail elsewhere (Schiff et al., 1987, 1990; Harris et al., 1989; Mackay et al., 1990). Radiation from a tunable diode laser is tuned, by varying the laser temperature and current, to a single rotational vibrational line in the infrared spectrum of the target species. This radiation is directed through a cell containing a flow of ambient air, maintained at a pressure of 25 torr or below, onto an infrared detector. Scanning the output frequency of the laser over the absorption feature allows the differential absorption, and hence the concentration, to be determined. To measure ambient air concentrations below a ppbv, both the path length and the minimum detectable absorption are optimized. In our instrument, a multiple reflection cell of the Horn and Pimental type (Horn and Pimental, 1971) with a path length of approximately $150 \mathrm{~m}$ for a $1.5 \mathrm{~m}$ base path is used. The detection was optimized by frequency modulating the laser and detecting the absorption signal at twice the modulation frequency, the so-called $2 \mathrm{f}$ scheme. (The recent development of pure frequency modulation schemes means this method is now becoming described as wavelength modulation.) The use of a computer to acquire and analyse data means that we were able to obtain detection limits routinely and precisions for $\mathrm{CH}_{2} \mathrm{O}$ and $\mathrm{H}_{2} \mathrm{O}_{2}$ of better than $0.2 \mathrm{ppbv}$ for the $30-\mathrm{min}$ averages reported here. The system was calibrated by adding a known concentration of the target molecule, from a permeation device, to the ambient air at the inlet. This has the effect of not only calibrating the cell but also calibrating out any first-order losses in the inlet system. The permeation devices in turn were calibrated by collecting the emitted gas and analysing it colorimetrically. The accuracy of the measurements above the detection limit was estimated to be $\pm 20 \%$ arising largely from the determination of the permeation rates. Details of these procedures for formaldehyde and hydrogen peroxide are in Harris et al. (1989) and Slemr et al. (1986), respectively.

PAN was measured using a gas chromatograph (GC) with electron capture detection. Air was drawn through a $5-\mu \mathrm{m}$ Teflon filter to remove particulate matter. Separation was achieved using a glass column $(6.3 \mathrm{~mm}$ o.d., $105 \mathrm{~cm}$ length) packed with $10 \%$ Carbowax on Chromosorb G-AW with $5 \% \mathrm{CH}_{4}$ in argon at a flow rate of $65 \mathrm{~cm}^{3} \mathrm{~min}^{-1}$ as the carrier gas. The column was maintained at $35^{\circ} \mathrm{C}$ and the Valco model $140 \mathrm{BN} \mathrm{ECD}$ detector at $50^{\circ} \mathrm{C}$. Injections of $5-\mathrm{ml}$ air samples were made every $40 \mathrm{~min}$. The PAN retention time was $\approx 4 \mathrm{~min}$ and the peaks integrated by a HP3390 integrator. Calibrations were conducted using known concentration PAN/air samples, generated using a solution of PAN in dodecane that was purified by preparative $\mathrm{GC}$, in a flowing mixture of zero air. The PAN was quantified using a chemiluminescence $\mathrm{NO}_{x}$ monitor as described in Blanchard $e t$ al. (1990). The estimated uncertainty in the concentrations reported here is $\pm 20 \%$ for measurements more than three times the detection limit of 0.01 ppbv.

Ozone was measured using an ultraviolet absorption ozone analyser (Dasibi Model 1003-AH) calibrated against the APIOS ozone standard. Solar ultraviolet radiation was measured using an ultraviolet radiometer (Eppley Labs, $280-320 \mathrm{~nm}$ ). This was used solely as a relative measure since the calibration is now some 6 years old and these radiometers are known to be subject to drifts. Meteorological parameters, wind speed, wind direction, temperature and relative humidity were obtained from a commercial meteorological system (MetOne). Boundary layer heights were obtained from an Aerovironment Inc. monostatic acoustic sounder (Tombach et al., 1973). This instrument directs $100 \mathrm{~ms}$ acoustic pulses, of $1600 \mathrm{~Hz}$, vertically into the atmosphere. Since the source and receiver are co-located, scattering from thermal fuctuations in the atmosphere dominates the received signal allowing temperature variations to be determined.

The acoustic sounder was located in its own hut to protect it from the wind. The other instrumentation, with the exception of PAN, was housed in a trailer which was some $50 \mathrm{~m}$ from the nearest building. The meteorological instrumentation was mounted on a pole $15 \mathrm{ft}$ above the ground, with the signals processed and recorded by computer inside the trailer. Air for the other instruments was brought down a 2 in. diameter glass tube from the top of a tower, $20 \mathrm{ft}$ above the surface, at a flow rate of nearly $800 \ell \mathrm{min}^{-1}$ giving a residence time prior to sampling of less than a second. A manifold inside the trailer allowed individual instruments to sample air against the flow to discriminate against large particles or droplets. The PAN instrument was located in the APIOS building $20 \mathrm{~m}$ from the trailer. In this case samples were drawn from a glass manifold that reached $4 \mathrm{~m}$ above the surface.

The presence of the NBL was determined from the acoustic sounder data. During the day the sounder showed very variable reflections typical of a highly convective boundary layer. At night the presence of the NBL was identified by the characteristic high reflectivity in a shallow layer above the surface. The top of the NBL was taken to be the height at which there was an abrupt change to an absence of reflections, as expected from the transition to a region of constant potential temperature.

\section{RESULTS AND DISCUSSION}

\section{The development of a nocturnal boundary layer}

The cooling of the ground, as the solar radiation decreases in the afternoon, results in a cooling of the bottom part of the planetary boundary layer and the production of a stable boundary layer commonly known as the nocturnal boundary layer (Stull, 1988). Such layers are known to be a frequent occurrence, predominantly in cases where the area is under the influence of a high-pressure system. Here the skies are clear, and the wind speed is low which encourages radiative cooling of the surface and the slow loss of heat from the air to the surface. In principle, the NBL is a layer of stable air, up to a few hundred metres 
thick, which serves to isolate the bulk of the air in the atmosphere from the surface. An NBL over perfectly flat terrain should yield stable stratification and very little turbulence so that even gases within the NBL would not contact the surface, and thus would experience no loss by dry deposition. However, the question of the degree to which turbulence occurs within this layer under real conditions has been the object of a great deal of study. The existence of sloping ground can produce a wind and associated turbulence where little or no wind is otherwise present. The cold air in contact with the surface will accelerate down the slope and set up what are commonly known as drainage winds, gravity flows, slope flows or katabatic winds. In the absence of a bulk flow, drainage wind speeds are typically $0.5-3.5 \mathrm{~m} \mathrm{~s}^{-1}$ (Stull, 1988). Even for apparently flat terrain, with slopes $(\Delta z / \Delta x)$ of $0.001-0.01$, drainage winds of $1-2 \mathrm{~ms}^{-1}$ are possible (Brost and Wyngaard, 1978). This suggests that in the
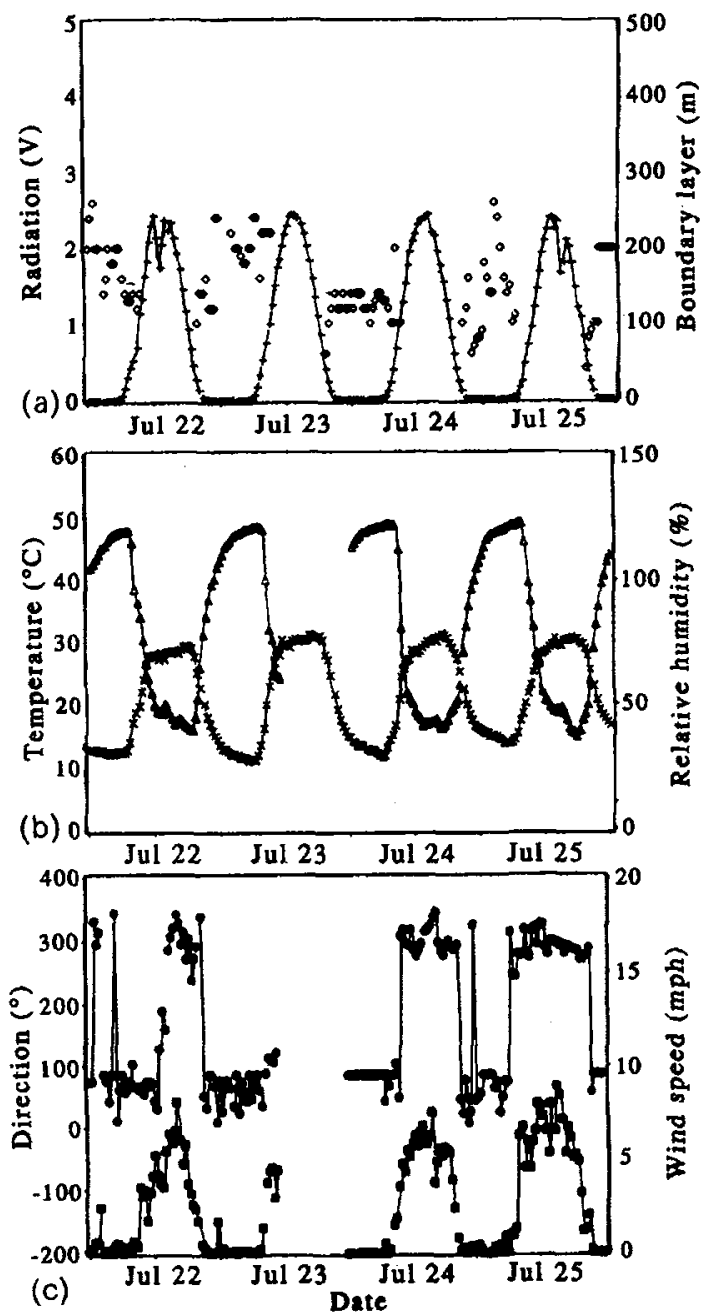

Fig. 1. Meteorological measurements for the period 22-25 July 1989. (a) Solar ultraviolet radiation $(+)$ and NBL height $(\diamond)$. (b) Temperature $(x)$ and humidity $(\Delta)$. (c) Wind speed $(0)$ and direction $(\bullet)$. presence of even the most gentle of slopes and for long averaging periods, there is enough turbulence generation in the NBL that it can act as a single well-mixed entity rather than a group of completely decoupled layers (Stull, 1988). The situation is most marked in a valley where there are drainage winds down the sides and the axis of the valley, balanced by the upward motion of air in the centre of the valley which, depending of the depth of the NBL compared to the valley depth, may penetrate the top of the NBL. Thus, contrary to popular belief, the continual overturning of air means that the intensity of the inversion in a valley is not as great as for level terrain (Munn, 1966). Whatever the terrain, the net effect of the turbulence in the NBL is that, for almost all measurement sites, the surface measurements are made on an air mass that is continually mixed up to only a few hundred metres but decoupled from the remainder of the planetary boundary layer. The main exception which yields a very stratified NBL is one of extreme flatness, such as a water surface.

The highest points surrounding the Dorset site in terms of height above, and distance from the site, are of $67 \mathrm{~m}$ at $100 \mathrm{~m}, 65 \mathrm{~m}$ at $500 \mathrm{~m}, 81 \mathrm{~m}$ at $500 \mathrm{~m}$, and $89 \mathrm{~m}$ at $1000 \mathrm{~m}$ so the greatest slope in the immediate vicinity is about $30^{\circ}$ with the others being less than $10^{\circ}$. These slopes appear sufficient to generate significant drainage winds and turbulence within the NBL which may allow us to consider it as being mixed, particularly if we consider only time scales in the order of hours.

The properties of typical NBLs at Dorset can be seen from the data from noon on 22 July 1989 to noon on 25 July 1989 which covers three nights that all indicate well-defined NBLs. Figure 1 shows the meteorological parameters that are available to characterize the features of the NBL. Figure 1a shows the solar ultraviolet irradiance and the height of the top of NBL as measured by the acoustic sounder. Based on the strength of the returns to the sounder these inversions are best described as being of medium strength and show some undulation in height, in the order of tens of metres, on a time scale faster than the 30 -min averages used here. The depth of the NBL is between 100 and $200 \mathrm{~m}$ above the site and since the highest point in the immediate area is $89 \mathrm{~m}$ above the site, the top of the inversion was always well above the top of the surrounding hills. In all cases the inversion was surface based, except during the break-up period, and began to develop slightly before sunset. These observations are consistent with those reported for other natural (non-urban) surfaces (Surridge and Swanepoel, 1987). The inversion reached its maximum depth, typically $100-220 \mathrm{~m}$ but in stronger cases $160-220 \mathrm{~m}$, within a couple of hours of the inversion onset. The expected square root dependence of NBL height on time was not observed here, nor did the observations show the 6-h development as seen by Godowitch et al. (1985). In the later study, helicopter 
temperature measurements were used to define the depth of the NBL, a technique which would likely be much more sensitive than the acoustic sounder used in this study. Consequently, we attach no significance to these measured differences.

Following sunrise the warming of the surface served to break up the NBL. This break-up was generally rapid, within $1 \mathrm{~h}$, and started from the surface. Occasionally an elevated inversion was observed as both the base and top of the inversion rose as it weakened. The inversion began to break up about $3 \mathrm{~h}$ after detectable sunrise which is much later than the $1 \mathrm{~h}$ observed by Godowitch et al. (1985) although the total time between sunrise and the complete disappearance of the inversion was about the same, $\sim 4 \mathrm{~h}$. Again the resolution of the temperature measurements would be expected to herald the inversion break-up before the acoustic sounder. Figures $1 \mathrm{~b}$ and $1 \mathrm{c}$ show the corresponding temperature, relative humidity, wind speed and wind direction changes over this period. The temperature dropped from daytime maxima of around $30-10^{\circ} \mathrm{C}$ during the night and the relative humidity rose from $40 \%$ to detector saturation. The temperature decrease alone is sufficient to account for this high relative humidity. The wind speed decreased from daytime values in excess of $8 \mathrm{mph}$ to below detectable levels at night. There is an indication of a change in wind direction as the wind speed drops but this cannot be confirmed as the direction sensor is notoriously unreliable at the lower wind speeds.

Similar behaviour was observed in the spring of 1990. In the early part of the campaign, when the temperatures were generally low, the acoustic sounder was operational and indicated only infrequent, weak inversions with heights around $200 \mathrm{~m}$. However, later in the study, for example 25-28 April, more summerlike conditions were encountered, i.e. the presence of an almost stationary high-pressure system, and strong NBLs were indicated. The temperature varied from the high 20 s during the day to below $10^{\circ} \mathrm{C}$ at night, the wind speed dropped, and the humidity rose in the same relationship to the sunset and sunrise as found in the summer study. Unfortunately, the acoustic sounder was inoperative for this period.

These data are typical of many nights during which measurements were made. On the basis of the existing sounding data, and the consistency of the chemical data described below, we estimate that medium to strong inversions took place on 20 of the 43 summer nights on which measurements were made. For the spring measurements, inversions were less frequent, being present on only 8 of 46 nights.

\section{Effect of the NBL on the concentration of reactive trace species}

The NBL traps a relatively shallow part of the mixed layer close to the surface, and isolates it from the rest of the mixed layer which itself is isolated from the surface. Thus surface-based chemical or physical effects have a much greater impact on the measured surface concentrations of reactive species under the NBL, than when there is better vertical transport. All the reactive species examined here showed a decrease in concentration under the NBL due to physical and chemical removal processes. The break-up of the NBL resulted in downward mixing of the air aloft and tended to restore the surface concentrations to those existing in the bulk of the mixed layer.

Ozone. For cases where the NBL was clearly formed, the $\mathrm{O}_{3}$ behaviour was very marked and reproducible. Figure 2 shows the $\mathrm{O}_{3}$ concentrations plotted with the solar ultraviolet irradiance for the two periods described above. In the summertime (Fig. 2a) the daytime maxima for $\mathrm{O}_{3}$ ranged from 47 to $60 \mathrm{ppbv}$ but for each of the three nights the concentration dropped to below 20 ppbv. The daytime $\mathrm{O}_{3}$ concentrations were relatively constant indicating little net photochemical production. The most notable feature is the decrease starting a little before sunset, the time of the first appearance of the NBL. During the formation, and for the duration of the nocturnal inversion, the $\mathrm{O}_{3}$ decreased by as much as a factor of three, reaching its minimum immediately prior to sunrise. Shortly after sunrise, upon the break-up of the inversion, the $\mathrm{O}_{3}$ concentration rose rapidly to values more typical of those of the previous day. Increases of $20 \mathrm{ppbv}$ in $2 \mathrm{~h}$ were common. During the afternoon there was little change in $\mathrm{O}_{3}$ concentration so the observed diurnal variation appeared to be governed
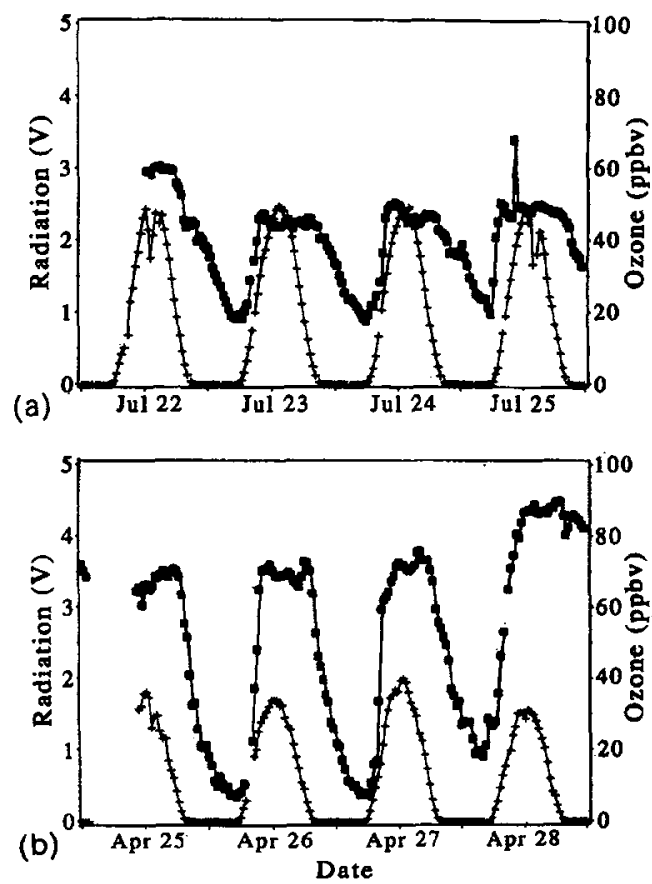

Fig. 2. Ozone concentration ( $)$ and solar ultraviolet radiation $(+)$ for (a) $22-25$ July 1989 and (b) 25-28 April 1990. 
largely by the NBL. Similar behaviour is seen in the spring data (Fig. 2b). The daytime $\mathrm{O}_{3}$ maxima were around $70 \mathrm{ppbv}$ and the nighttime minima were again below 20 ppbv with two of the three nights showing $\mathrm{O}_{3}$ concentrations below $10 \mathrm{ppbv}$.

This kind of $\mathrm{O}_{3}$ behaviour has been well documented (e.g. Cox et al., 1975; Harrison et al., 1978; Oltmans, 1981; Kelly et al., 1984; Broder and Gygax, 1985; Broder et al., 1981; Fehsenfeld et al., 1983; Lifshitz et al., 1988; Shepson et al., 1992b). The decrease has been attributed to the $\mathrm{O}_{3}$, isolated within the NBL, depositing to the surface and reacting with freshly emitted NO under the inversion. In the morning the rapid rise in $\mathrm{O}_{3}$ concentration is due to the break-up of the NBL allowing the undepleted air from aloft to be sampled. There is very little vehicular traffic in the area surrounding the Dorset site, so local anthropogenic NO sources are unlikely to be important in nighttime $\mathrm{O}_{3}$ loss. Measurements of Shepherd et al. (1990) show that the nighttime soil production of NO at the site is also of no significance, even in the summer. Thus we would expect, for this location, the loss of $\mathrm{O}_{3}$ under the inversion to be dominated by loss to the surface. If one assumes that the drainage winds, and the other effects generating turbulence, are sufficient for a well-mixed NBL, at least on the scale of hours, then it is possible to determine loss rates from within the layer to test if the rate of loss is consistent with a surface loss alone. For the specific nights described above, plots of $\ln$ (ozone concentration) against time for the duration of each of the inversion events gave a straight line, with $\boldsymbol{r}^{2} \geqslant 0.9$ showing the loss process to be truly first order (see Table 1).

An effective deposition velocity $\left(v_{\mathrm{d}}\right)$ can be determined from the slope of this line, $k$, and the NBL depth, $h$. However, the definition of the deposition velocity at night poses a problem, because the combination of the slow mixing under the NBL and the deposition produces a strong vertical concentration gradient. Thus there is no absolute deposition velocity, as its value depends on the height that is chosen as defining the average concentration. We have used the average $\mathrm{O}_{3}$ concentration within the NBL in the determination of $v_{\mathrm{d}}$. To obtain this average we have assumed a linear decrease in ozone concentration with height, similar to that observed by Colbeck and Harrison (1985) and Broder and Gygax (1985), in which case $v_{\mathrm{d}}$ is given by $k h / 2$. The values calculated in this way are directly comparable with those obtained by Broder and Gygax (1985) and Shepson et al. (1992b) but will be a factor of two lower than those of Kelly et al. (1984), who define $v_{d}$ in terms of the surface concentration. The results of the determination of $v_{\mathrm{d}}$ are also presented in Table 1 . There were no NBL depth measurements in spring 1990 , but since the temperature variations were similar to those in the summer, an average depth from the summer data was assumed. The effective deposition velocities determined are less than $0.6 \mathrm{~cm} \mathrm{~s}^{-1}$ and so are consistent with a surface loss process alone. While these values are of the same order as deposition velocities determined by a number of workers (e.g. Galbally and Roy, 1980; Colbeck and Harrison, 1985; Neumann and den Hartog, 1985), these values should not be construed in any way as typical deposition velocities. Firstly, they are nighttime values and Galbally and Roy (1980) have shown that the surface resistance of vegetation to $\mathrm{O}_{3}$ uptake is up to a factor of two higher at night than in the daytime. More importantly the turbulence regime for these measurements is very poorly defined and while the aerodynamic resistance is highly important, it cannot be calculated. Using similar procedures, Kelly et al. (1984) obtained nighttime deposition velocities of $0.06-0.34 \mathrm{~cm} \mathrm{~s}^{-1}(0.03-0.17$ using our method) and Broder and Gygax (1985) quote an average value of $0.44 \mathrm{~cm} \mathrm{~s}^{-1}$. The higher values reported here, and at the valley site (Broder and Gygax, 1985), point to the importance of the drainage flow in determining the deposition velocities.

Hydrogen peroxide. Hydrogen peroxide is a product of $\mathrm{HO}_{2}$ radical recombination, but its production is in competition with the oxidation of NO. Thus its pro-

Table 1. Ozone deposition under the nocturnal boundary layer

\begin{tabular}{lccc}
\hline & $\begin{array}{c}\text { Inversion } \\
\text { height } \\
\text { (estimated) } \\
\text { Date }\end{array}$ & $\begin{array}{c}\text { Regression slope }\left(r^{2}\right) \\
\left(\mathrm{s}^{-1}\right)\end{array}$ & $\begin{array}{c}\text { Calculated } \\
\text { ozone } \\
\text { deposition } \\
\text { velocity } \\
\left(\mathrm{cm} \mathrm{s}^{-1}\right)\end{array}$ \\
\hline 22-23 July 1989 & 200 & $-2.95 \times 10^{-5}(0.95)$ & 0.30 \\
23-24 July 1989 & 130 & $-2.72 \times 10^{-5}(0.98)$ & 0.18 \\
24-25 July 1989 & 125 & $-2.03 \times 10^{-5}(0.89)$ & 0.19 \\
25-26 April 1990 & $(160)$ & $-6.1 \times 10^{-5}(0.96)$ & 0.49 \\
26-27 April 1990 & $(160)$ & $-6.8 \times 10^{-5}(0.97)$ & 0.54 \\
27-28 April 1990 & $(160)$ & $-3.9 \times 10^{-5}(0.93)$ & 0.31 \\
\hline
\end{tabular}

The regression slopes are the slopes of the regression of the $\ln \left(\mathrm{O}_{3}\right.$ concentration) against time after the formation of the NBL. The deposition velocity was determined by multiplying the regression slope by half the inversion height (see text). 
duction rate is a complex function of the level of photochemical activity and air mass age. Furthermore, it is extremely water soluble and is generally removed by wet deposition and thus has a relatively short atmospheric lifetime. Consequently, $\mathrm{H}_{2} \mathrm{O}_{2}$ is commonly measured in oxidant programs, as the combination of rapid production and removal mean that predicting $\mathrm{H}_{2} \mathrm{O}_{2}$ concentrations can be a rigorous test of model performance.

Plots of the $\mathrm{H}_{2} \mathrm{O}_{2}$ concentration for the two periods under consideration are shown, with the corresponding $\mathrm{O}_{3}$ data, in Fig. 3. In both these periods the $\mathrm{H}_{2} \mathrm{O}_{2}$ concentration showed a strong diurnal variation with a maximum during the day decreasing to below the detection limit at night. It should be noted that for the spring campaign these daytime data were atypically high; generally little or no $\mathrm{H}_{2} \mathrm{O}_{2}$ was detected. In this study the smooth rise in concentration during the morning to the early afternoon maximum is similar to that expected for photochemical production, but there is a problem in that the other species (e.g. $\mathrm{O}_{3}$ ) show no such production. The decrease at sunset is similar to that of $\mathrm{O}_{3}$ suggesting surface loss. However, there are marked differences in the behaviour of the two species. The decrease in $\mathrm{H}_{2} \mathrm{O}_{2}$ appears to take place earlier and more rapidly than for $\mathrm{O}_{3}$, and is far faster than could be accounted for with a sensible surface deposition velocity. Also the increase in $\mathrm{H}_{2} \mathrm{O}_{2}$ following the break-up of the inversion appears delayed with respect to that of $\mathrm{O}_{3}$. If the morning increase is, as described above, due to the downward transport of reactive gases from above the NBL, then the two species should increase in concert. There is clearly another mechanism controlling the $\mathrm{H}_{2} \mathrm{O}_{2}$ concentration. Figures 4 and 5 show there is a very strong anticorrelation between the $\mathrm{H}_{2} \mathrm{O}_{2}$ concentration and the relative humidity. In particular, the increases and decreases in $\mathrm{H}_{2} \mathrm{O}_{2}$ are coincident with the transitions in the humidity from the daytime values of below $50 \%$ to the saturated conditions at night, with significant gasphase $\mathrm{H}_{2} \mathrm{O}_{2}$ only existing for relative humidities below $60 \%$. Furthermore, although there are many parameters changing at the same time, the correlation between $\mathrm{H}_{2} \mathrm{O}_{2}$ and relative humidity is the only one where there was no time delay between the rapid concentration changes. This suggests that $\mathrm{H}_{2} \mathrm{O}_{2}$ is being removed from the gas phase by aqueous aerosol. The high solubility of $\mathrm{H}_{2} \mathrm{O}_{2}$ compared to $\mathrm{O}_{3}$ (their Henry's law coefficients are $10^{5}$ and $10^{-2} \mathrm{M} \mathrm{atm}^{-1}$, respectively) would explain the apparent higher sensitivity of $\mathrm{H}_{2} \mathrm{O}_{2}$ concentration to relative humidity. Measurements of aerosol concentration and composition would tell if the aerosol is sufficiently deliquescent and has enough surface area for this process to be efficient, however such measurement data are unavailable.

A reasonable explanation for the observed $\mathrm{H}_{2} \mathrm{O}_{2}$ profiles is that at sunset, and as the nocturnal inversion forms, water condenses on the particles present in the atmosphere, and the aqueous aerosol efficiently scavenges the highly soluble $\mathrm{H}_{2} \mathrm{O}_{2}$. There is no $\mathrm{H}_{2} \mathrm{O}_{2}$ loss to aqueous aerosol above the $\mathrm{NBL}$, as the temperature change overnight is much smaller. Also, photochemical $\mathrm{H}_{2} \mathrm{O}_{2}$ destruction diminishes at night so the

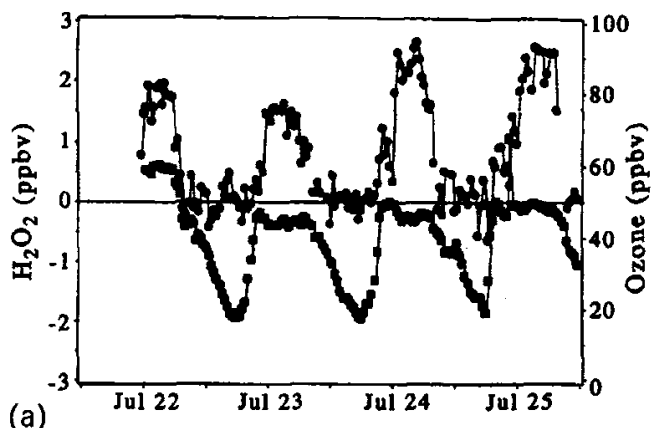

(a)

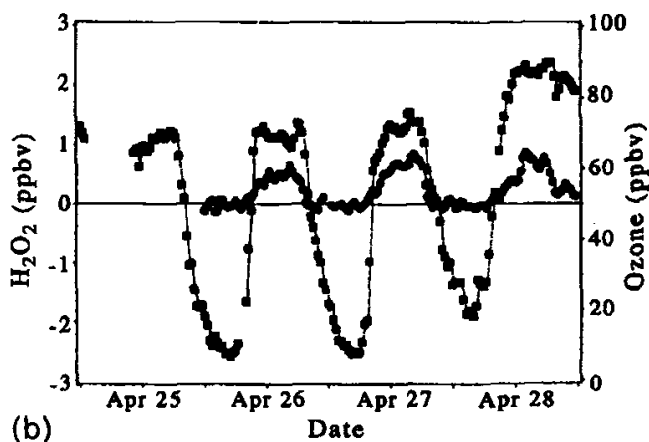

Fig. 3. $\mathrm{H}_{2} \mathrm{O}_{2}$ (๑) and $\mathrm{O}_{3}$ (四) concentrations for (a) 22-25 July 1989 and (b) 25-28 April 1990.
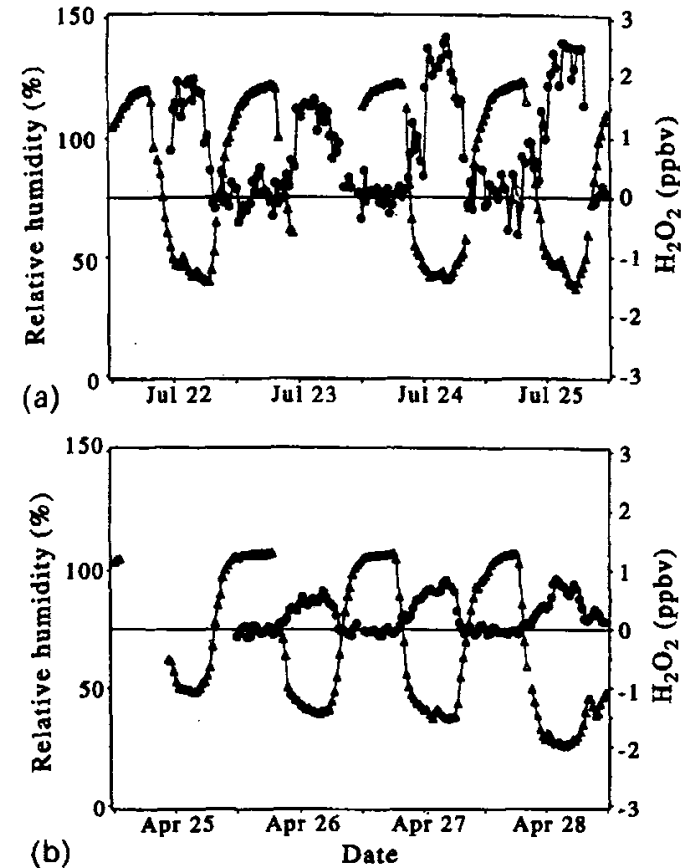

Fig. 4. $\mathrm{H}_{2} \mathrm{O}_{2}$ concentration (e) and relative humidity (A) for (a) 22-25 July 1989 and (b) 25-28 April 1990 . 

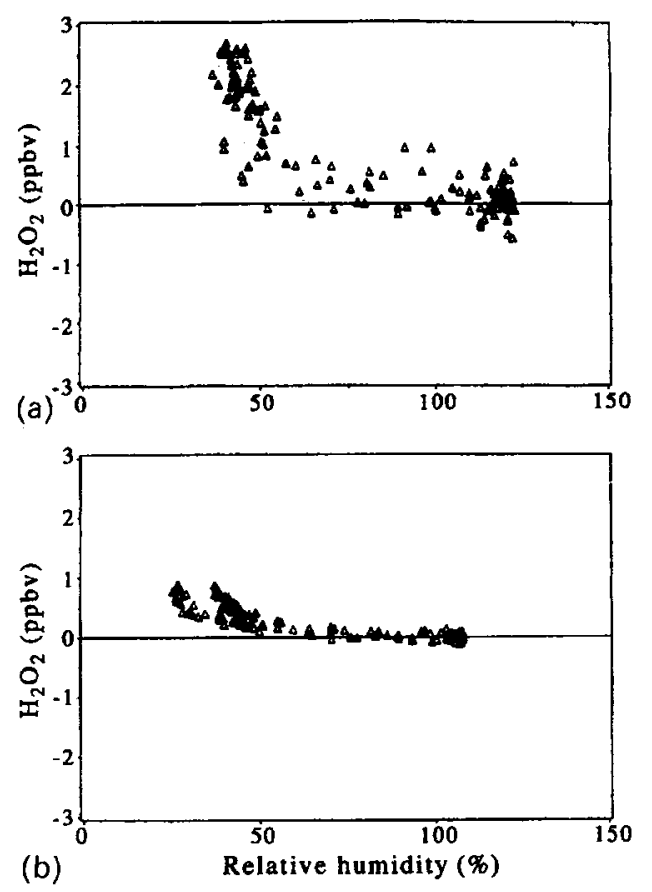

Fig. 5. $\mathrm{H}_{2} \mathrm{O}_{2}$ concentration as a function of relative humidity for (a) 22-25 July 1989 and (b) 25-28 April 1990.

$\mathrm{H}_{2} \mathrm{O}_{2}$ concentration remains unchanged above the NBL. As the inversion breaks up in the morning, the air entrained from above mixes with air from within the NBL which still contains an appreciable amount of the aqueous aerosol. The initial $\mathrm{H}_{2} \mathrm{O}_{2}$ transported downwards will be absorbed into the aerosol and not detected. Only after the relative humidity has dropped below that necessary for aqueous aerosol formation can entrainment from above increase the $\mathrm{H}_{2} \mathrm{O}_{2}$ concentration.

$P A N$. Figure 6 shows the PAN data, plotted along with the $\mathrm{O}_{3}$ data, for the two periods. There is much less PAN in the summer period, likely due to the higher thermal decomposition rate at the higher temperatures. After sunset $\mathrm{O}_{3}$ and PAN show identical variations pointing to PAN loss under the NBL. As was the case with $\mathrm{O}_{3}$, the lack of NO production at night indicates deposition to the surface is a major factor controlling the PAN concentration. However, there is a major difference at the break-up of the inversion where, in the spring, an early morning concentration maximum was observed. While the break-up of the NBL can explain the increase in the concentration over nighttime levels it cannot explain a morning maximum, unless there was a maximum in the PAN profile with height prior to the break-up. This site is removed from source regions and so layers of elevated pollutant concentrations are not expected. Thus the presence of a maximum in the PAN concentration must be due to either an early morning PAN source, in addition to the entrainment from aloft, or a
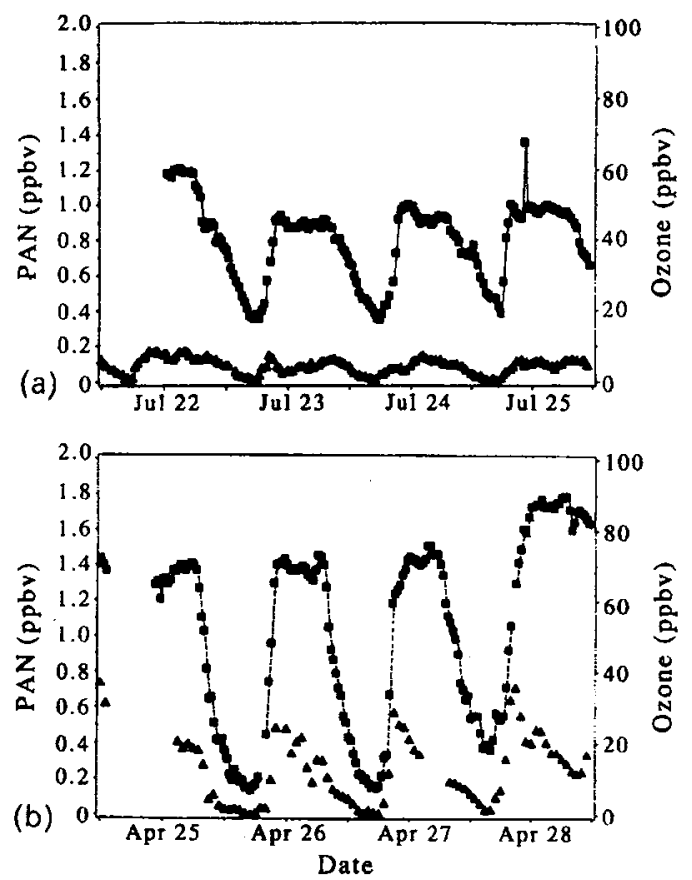

Fig. 6. PAN $(\Delta)$ and $\mathrm{O}_{3}(\square)$ concentrations for (a) 22-25 July 1989 and (b) 25-28 April 1990.

loss in the PAN after it was transported to the surface.

The $\mathrm{H}_{2} \mathrm{O}_{2}$ data show there is little chemical activity in the early morning so there is no evidence to support an early morning chemical source of PAN. Thus PAN destruction after the entrainment from above must be responsible for the morning maximum. It is likely that the PAN transported from aloft experienced markedly different conditions than those above the NBL at night. The temperature was several degrees higher at the surface and, since the thermal decomposition of PAN is extremely temperature dependent, the rate of thermal decomposition would be expected to increase. In addition the concentration of NO would be higher than at night, due to $\mathrm{NO}_{2}$ photolysis, so the rate of peroxyacetyl radical removal by NO would also increase. The combination of these two effects would result in a large increase in the net rate of PAN loss on downward entrainment. In the spring period, when there appears to be little active photochemistry, the PAN concentration would decrease. In more reactive systems this effect would be masked by the onset of PAN production from the hydrocarbon oxidation chemistry.

Thus the early morning peak, predominant in the spring data set, can be attributed to first an increase due to entrainment from above followed by an increased loss due to thermal decomposition and radical loss through reaction with NO.

Formaldehyde. The plots of $\mathrm{CH}_{2} \mathrm{O}$ are shown in Fig. 7 along with $\mathrm{O}_{3}$ for ease of comparison. Following the break-up of the $\mathrm{NBL}$ the $\mathrm{CH}_{2} \mathrm{O}$ concentration rose on 

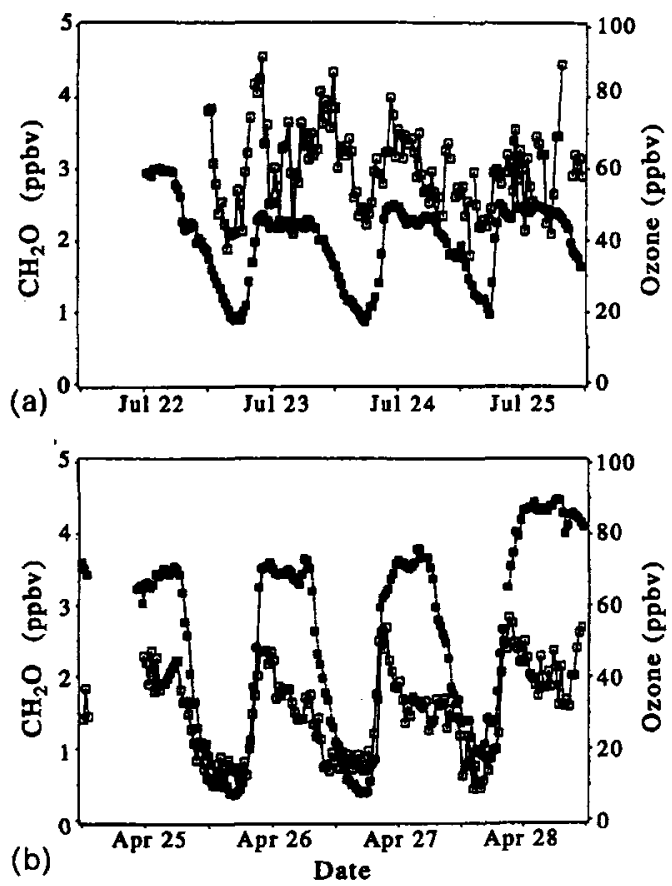

Fig. 7. $\mathrm{CH}_{2} \mathrm{O}(\square)$ and $\mathrm{O}_{3}(\square)$ concentrations for (a) 22-25 July 1989 and (b) 25-28 April 1990.

exactly the same time scale as the $\mathrm{O}_{3}$ indicating the same source, entrainment from aloft. The spring $\mathrm{CH}_{2} \mathrm{O}$ data showed great similarity to that observed for PAN. Both the morning maximum, and a good deal of the small-scale concentration variations are the same for $\mathrm{CH}_{2} \mathrm{O}$ and PAN.

Since both $\mathrm{CH}_{2} \mathrm{O}$ and PAN arise from oxidation chemistry, a correlation between their concentrations would be expected. However, the absence of similar relationships with $\mathrm{O}_{3}$ and $\mathrm{H}_{2} \mathrm{O}_{2}$ suggest that $\mathrm{CH}_{2} \mathrm{O}$ is behaving as more than just an indicator of polluted air. As with PAN, the early morning maximum indicates that either there is an early morning source of $\mathrm{CH}_{2} \mathrm{O}$, or a loss mechanism in the morning. The evaporation of water at this time does not release enough $\mathrm{CH}_{2} \mathrm{O}$ to explain the increase. For a fog liquid water content of $0.1 \mathrm{~g} \mathrm{~m}^{-3}$, the amount of $\mathrm{CH}_{2} \mathrm{O}$ in the aqueous phase is only $1.5 \%$ of that in the gas phase. Loss of $\mathrm{CH}_{2} \mathrm{O}$ by photolysis is too slow, in the morning, to account for such a decrease. This then indicates a chemical explanation for the morning $\mathrm{CH}_{2} \mathrm{O}$ maximum.

The formaldehyde chemistry, in the morning, is complex, especially if the decomposition of PAN is occurring. Formaldehyde is being brought down from aloft, it is produced from PAN decomposition, it is being photolysed, and the radicals from PAN decomposition and ozone photolysis are initiating the oxidant chemistry that can both produce and destroy $\mathrm{CH}_{2}$ O. This data set is too small to confirm the dominant processes; more detailed investigations are required.

\section{CONCLUSIONS AND RECOMMENDATIONS}

The nocturnal boundary layer has a marked impact on the concentration of the secondary species, at the Dorset site. In cases where the NBL is well established, $\mathrm{O}_{3}, \mathrm{PAN}$ and $\mathrm{CH}_{2} \mathrm{O}$ appear to be deposited to the surface resulting in depleted mixing ratios in the air under the NBL. For $\mathrm{H}_{2} \mathrm{O}_{2}$, we believe the increase in humidity resulting from the cooling of the air in the NBL produces aqueous aerosol into which the peroxide dissolves, resulting in a very rapid gas phase loss. There is no measurable gas-phase $\mathrm{H}_{2} \mathrm{O}_{2}$ existing at relative humidities greater than $60 \%$. In the morning, when the inversion breaks up, air from above is entrained downwards rapidly increasing the surfacelevel concentrations. The slow evaporation of the aqueous aerosol delays the rise in $\mathrm{H}_{2} \mathrm{O}_{2}$ concentrations. For PAN in the spring, there is evidence that the high concentrations coming from aloft were decreased, probably by thermal decomposition followed by chemical loss of peroxyacetyl radicals. The $\mathrm{CH}_{2} \mathrm{O}$ concentration followed that of PAN, not only on the break-up of the inversion but throughout the day.

The impact of the NBL on the concentrations of the reactive species makes it clear that measurements taken under the NBL are not representative of the entire planetary boundary layer. For studies where such representativeness is required, it is necessary to eliminate data collected under an NBL, and also that where the humidity is still stabilizing after the morning NBL break-up.

While the NBL can preclude the gaining of some regional-scale data, the isolation of small air masses and the subsequent mixing with the rest of the planetary boundary layer can yield information that is otherwise not available.

Acknowledgements--This is scientific contribution no. 92-23 of the Canadian Institute for Research in Atmospheric Chemistry (CIRAC). The work described herein was undertaken as part of the CIRAC CACE project and was supported by a grant from the Ontario Ministry of the Environment. We wish to thank J. P. Varto, J. Jones and all the scientists and staff at the Dorset Research Centre for their support on site; R. Berman, S. Malle, D. Toom and K. So of York University for their work in gathering and analysing the data; and M. Lusis, N. Reid and G. Harris, for helpful discussions. In particular we want to thank $O$. Melo, G. Ogram and C. Donovan for the use and maintenance of the acoustic sounder.

\section{REFERENCES}

Blanchard P., Shepson P. B., So K. W., Schiff H. I., Bottenheim J. W., Gallant A. J., Drummond J. W. and Wong P. (1990) A comparison of calibration and measurement techniques for gas chromatographic detection of atmospheric peroxyacetyl nitrate (PAN). Atmospheric Environment 24A, 2839-2846.

Broder B. and Gygax H. A. (1985) The influence of locally induced wind systems on the effectiveness of nocturnal dry deposition of ozone. Atmospheric Environment 19, 1627-1637. 
Broder B., Dütsch H. U. and Graber W. (1981) Ozone fluxes in the nocturnal boundary layer over hilly terrain. Atmospheric Environment 15, 1195-1199.

Brost R. A. and Wyngaard J. C. (1978) A model study of the stably stratified planetary boundary layer. J. atmos. Sci. 35, $1427-1440$.

Claiborne C. S. and Aneja V. P. (1991) Measurements of atmospheric hydrogen peroxide in the gas phase and in cloud water at Mt Mitchell, North Carolina. J. geophys. Res. 96, 18771-18787.

Colbeck I. and Harrison R. M. (1985) Dry deposition of ozone: some measurements of dry deposition velocity and of vertical profiles to 100 meters. Atmospheric Environment 19, 1807-1818.

Cox R. A., Eggleton A. E. J., Derwent D. G., Lovelock J. E and Pack D. H. (1975) Long-range transport of photochemical ozone in north-western Europe. Nature 255, 118-121.

Das T. N., Moorthy P. N. and Rao K. N. (1983) Chemiluminescent measurement of atmospheric hydrogen peroxide in the Bombay area. Atmospheric Environment 17, 79-82.

Fehsenfeld F. C., Bollinger M. J., Liu S. C., Parrish D. D. McFarland M., Trainer M., Kley D., Murphy P. C. Albritton D. L. and Lenchow D. H. (1983) A study of ozone in the Colorado Mountains. J. atmos. Chem. 1, 87-105.

Galbally I. E. and Roy C. R. (1980) Destruction of ozone at the Earth's surface. Q JI.R. Met. Soc. 106, 599-620.

Godowitch J. M., Ching J. K. S. and Clark J. F. (1985) Evolution of the nocturnal inversion layer at an urban and nonurban location J. Clim. appl. Met. 24, 791-804.

Harris G. W., Mackay G. I., Iguchi T., Mayne L. K. and Schiff H. I. (1989) Measurements of formaldehyde in the troposphere by tunable diode laser absorption spectroscopy. J. atmos. Chem. 8, 119-137.

Harrison R. M., Holman C. D., McCartney H. A. and Mcliveen J. F. R. (1978) Nocturnal depletion of photochemical ozone at a rural site. Atmospheric Environmen 12, 2021-2026.

Horn D. and Pimentel G. C. (1971) A 2.5-km low-temperature multiple-reflection cell. Appl. Opt. 10, 1892-1898.

Jacob P., Tavares T. M., Rocha V. C. and Klockow D. (1990) Atmospheric $\mathrm{H}_{2} \mathrm{O}_{2}$ field measurements in a tropical environment: Bahia, Brazil. Atmospheric Environment 24A, 377-382.

Kelly N. A., Wolff G. T. and Ferman M. A. (1984) Sources and sinks of ozone in rural areas. Atmospheric Environment $18,1251-1266$.

Kins L. (1990) Measurements of gaseous hydrogen peroxide in southern Germany. In Physico-chemical Behaviour of Atmospheric Pollutants (edited by Restelli G. and Angelett G), pp. 535-540. Kluwer, Dordrecht.

Lifshitz B., Peleg M. and Luria M. (1988) The influence of medium-range transport on $\mathrm{O}_{3}$ levels at a rural site in Israel. J. atmos. Chem. 7, 19-33.

Mackay G. I., Mayne L. K. and Schiff H. I. (1990) Measurement of $\mathrm{H}_{2} \mathrm{O}_{2}$ and $\mathrm{HCHO}$ by tunable diode laser absorption spectroscopy during the 1986 carbonaceous species methods comparison study in Glendora, California Aerosol Sci. Technol. 12, 56.

Martin R. S., Westberg H., Allwine E., Ashman L., Farmer J. C. and Lamb B. (1991) Measurement of isoprene and its atmospheric oxidation products in a central Pennsylvania deciduous forest. J. atmos. Chem. 13, 1-13.
Munn R. E. (1966) Descriptive Micrometeorology, Adv. Geophys. Ser. Suppl. 1. Academic Press, New York.

Neumann H. H. and den Hartog G. (1985) Eddy correlation measurements of atmospheric fluxes of ozone, sulphur and particulates during the Champaign intercomparison study. J. geophys. Res. 90, 2097-2111.

Olszyna K. J., Meagher J. F. and Bailey E. M. (1988) Gasphase, cloud and rain-water measurements of hydrogen peroxide at a high-elevation site. Atmospheric Environment 22, 1699-1706.

Oltmans S. J. (1981) Surface measurements in clean air. $J$. geophys. Res. 86, 1174-1180.

Ridley B. A., Shetter J. D., Walega J. G, Madronich S. Elsworth, C. M., Grahek F. E., Fehsenfeld F. C., Norton R. B., Parrish D. D., Hübler G., Buhr M., Williams E. J., Allwine E. J. and Westberg H. H. (1990) The Behaviour of some organic nitrates at Boulder and Niwot Ridge, Colorado. J. geophys. Res. 95, 13949-13961.

Schiff H. I., Harris G. W. and Mackay G. I. (1987) Measurement of atmospheric gases by laser absorption spectrometry. In The Chemistry of Acid Rain: Sources and Atmospheric Processes, ACS Symp. Ser., Vol. 349 (edited by Johnson R. W. and Gordon G. E.), chap. 24, pp. 274-288. American Chemical Society, Washington, DC

Schiff H. I., Karecki D. R., Harris G. W., Hastie D. R, and Mackay G. I. (1990) A tunable diode laser system for aircraft measurements of trace gases. J. geophys. Res. 95, 10147-10153.

Shepherd M. F., Schiller C. L. and Hastie D. R. (1990) Measurement of $\mathrm{NO}_{x}$ emissions from soils. In Proc. National Oxidants Research Workshop, Canadian Institute for Research in Atmospheric Chemistry, June.

Shepson P. B., Hastie D. R., So K. W., Schiff H. I. and Wong P. (1992a) Relationship between PAN, PPN, and $O_{3}$ at urban and rural sites in Ontario. Atmospheric Environment 26A, 1259-1270

Shepson P. B., Bottenheim J. W., Hastie D. R. and Venkatram A. (1992b) Determination of the relative ozone and PAN deposition velocities at night. Geophys. Res. Lett. 19 , 1121-1124.

Singh H. B. and Salas L. J. (1989) Measurements of peroxyacetyl nitrate (PAN) and peroxypropionyl nitrate (PPN) at selected urban rural and remote sites. Atmospheric Environment 23, 231-238.

Slemr F., Harris G.W., Hastie D. R., Mackay G. I. and Schiff H. I. (1986) Measurement of gas phase hydrogen peroxide in air by tunable diode laser absorption spectroscopy. $J$. geophys. Res. 91, 5371-5378.

Stull R. B. (1988) An Introduction to Boundary Layer Meteorology. Kluwer, Dordrecht.

Surridge A. D. and Swanepoel D. J. (1987) On the evolution of the height and temperature difference across the nocturnal stable boundary layer. Boundary-Layer Met. 40, 8798.

Tanner R. L., Markovits G. Y., Ferreri E. M. and Kelly T. J. (1986) Sampling and determination of gas-phase hydrogen peroxide following removal of ozone by gas-phase reaction with nitric oxide. Analyt. Chem. 58, 1857-1865.

Tombach I., MacCready P. B. and Baboolal L. (1973) Use of a monostatic acoustic sounder in air pollution diffusion estimates. In Proc. 2nd Joint Conf. Sensing of Environmental Pollutants, Instrument Society of America, pp. 139-149. 